\title{
Hubungan Pendidikan dan Pendapatan Orang Tua dengan Pertumbuhan Balita
}

\author{
Yulia Nur Khayati, Sundari \\ Email: yulia.farras@gmail.com \\ DIII Kebidanan, Fakultas Ilmu Kesehatan, Universitas Ngudi Waluyo, Indonesia \\ J1. Diponegoro 186 Ungaran, Kab. Semarang \\ Telp. (024) 76914411
}

\begin{abstract}
Abstrak
Faktor yang mempengaruhi pertumbuhan dan perkembangan pada anak antara lain faktor internal, faktor eksternal yaitu faktor prenatal, faktor persalinan, faktor pasca persalinan. Faktor prenatal meliputi gizi, mekanis, toksin, endoktrin, radiasi, psikologis ibu, sedangkan faktor pasca persalinan meliputi gizi, psikologis, lingkungan pergaulan dan stimulasi. Faktor keluarga dan adat istiadat yang didalam nya antara lain adalah pekerjaan dan pendapatan, pendidikan, serta pengetahuan orang tua. Tujuan penelitian ini adalah untuk mengetahui hubungan anatara pendidikan dan pendapatan orang tua dengan pertumbuhan balita yang diukue dengan menggunakan $\mathrm{BB} / \mathrm{TB}$ dan TB/U. Metode Penelitian ini menggunakan desain analitik observasional dengan pendekatan cross sectional. Sampel penelitian ini adalah balita usia $0-5$ tahun yang berjumlah 75 responden. Teknik pengumpulan data pengukuran pertumbuhan dengan menggunakan tabel pertumbuhan WHO yaitu menggunakan tinggi badan per umur $(\mathrm{TB} / \mathrm{U})$ dan Berat badan per tinggi badan $(\mathrm{BB} / \mathrm{TB})$, pekerjaan dan pendapatan orang tua dikumpulkan dengan menggunakan kuesioner dan dianalisis bivariat menggunakan uji chi Square.Hasil penelitian ini terdapat hubungan antara pendidikan dan pendapatan orang tua dengan pertumbuhan $(\mathrm{TB} / \mathrm{U})$, terdapat hubungan antara pendidikan orang tua dengan pertumbuhan $(\mathrm{BB} / \mathrm{TB})$, dan tidak terdapat hubungan antara pendapatan orang tua dengan pertumbuhan $(\mathrm{BB} / \mathrm{TB})$.
\end{abstract}

Kata Kunci: pertumbuhan; pendidikan dan pendapatan keluarga.

\begin{abstract}
The factors influencing the growth and development of children are internal factor, external factor which is prenatal factor, during giving birth factor and after giving birth factor. Prenatal factors include nutrition, mechanism, toxin, endoctrine, radiation, and mother's psychological condition, while for the factors after giving birth are nutrition, psychological condition, social environment and stimulation. Family and culture factors involve parents' job and income, educational levels and knowledge. The purpose of this research is to know the correlation between parents' educational levels and income with the growth of children under five measured by using Body Weight/Body Height (BB/TB) and Body Height/Age (TB/A). The method applied analytical observational using cross sectional approach. The samples were children under five aged 0-5 years as many as 75 respondents. The technique to collect the data used WHO's growth table consisting of body height per age (TB/U) and body weight per body height (BB/TB), parents' job and income were collected by using questionnaires and analyzed bivariately by using chi Square test. The results of this research showed a correlation between parents' educational levels and income with the growth $(\mathrm{TB} / \mathrm{U})$, a correlation between parents' educational levels and the growth of the children $(\mathrm{BB} / \mathrm{TB})$ and no correlation between parents' income with the growth of the children $(\mathrm{BB} / \mathrm{TB})$
\end{abstract}

Keywords: growth; education and family income. 
Jurnal Kebidanan Harapan Ibu Pekalongan

\section{Pendahuluan}

Upaya kesehatan anak bertujuan untuk mempersiapkan generasi sehat, cerdas dan berkualitas serta menurunkan angka kematian anak yang dilakukan dengan upaya pemeliharaan kesehatan anak sejak dalam kandungan, dilahirkan dan sampai anak berusia 18 tahun. ${ }^{(1)}$

Pertumbuhan dan perkembangan anak menjadi hal yang sangat penting untuk dilakukan pengawasan karena akan menjadi dasar kualitas generasi penerus bangsa. Secara global setiap tahun lebih dari 200 juta anak kurang dari 5 tahun menunjukkan keterlambatan perkembangan dan $86 \%$ terjadi di negara berkembang. Sekitar $43 \%$ anak di negara berkembang dikhawatirkan akan mengalami gangguan perkembangan. ${ }^{(2)(3)(4)}$

Masalah gizi, khususnya pada balita, menjadi masalah besar karena berkaitan erat dengan indikator kesehatan umum seperti tingginya angka kesakitan serta angka kematian bayi dan balita. Kelompok balita juga termasuk kelompok rentan gizi yaitu kelompok masyarakat yang paling mudah menderita kelainan gizi bila suatu masyarakat kekurangan penyediaan bahan makanan. ${ }^{(5)}$

Faktor yang mempengaruhi pertumbuhan dan perkembangan pada anak antara lain faktor internal, faktor eksternal yaitu faktor prenatal, faktor persalinan, faktor pasca persalinan. Faktor prenatal meliputi gizi, mekanis, toksin, endoktrin, radiasi, psikologis ibu, sedangkan faktor pasca persalinan meliputi gizi, psikologis, lingkungan pergaulan dan stimulasi. Faktor keluarga dan adat istiadat yang didalam nya anatara lain adalah pekerjaan dan pendapatan orang tua, pendidikan orang tua, serta pengetahuan orang tua. ${ }^{(3)}$

Pendapatan keluarga yang memadai akan menunjang tumbuh kembang anak, karena orangtua dapat menyediakan semua kebutuhan anak baik yang primer maupun yang sekunder sehingga kebutuhan anak dapat tercukupi ${ }^{(3)}$. Pendidikan orangtua merupakan salah satu faktor yang penting dalam proses pertumbuhan dan perkembangan anak, karena dengan pendidikan yang baik maka orangtua dapat lebih mudah menerima segala informasi dari luar terutama tentang cara pengasuhan anak yang baik, bagaimana menjaga kesehatan anaknya, atau pendidikannya. ${ }^{(3)}$

\section{Metode}

Penelitian ini menggunakan desain analitik observasional dengan pendekatan cross sectional. Penelitian dilaksanakan tanggal 11 Juni -21 Juli 2019 diwilayah kerja Puskesmas Ungaran, Leyangan dan Banyubiru. Sampel penelitian ini adalah balita usia $0-5$ tahun yang berjumlah 75 responden.Teknik pengumpulan data pengukuran pertumbuhan dengan menggunakan tabel pertumbuhan WHO yaitu menggunakan tinggi badan per umur $(\mathrm{TB} / \mathrm{U})$ dan Berat badan per tinggi badan $(\mathrm{BB} / \mathrm{TB})$, pekerjaan dan pendapatan orang tua dikumpulkan dengan menggunakan kuesioner. Hasil Penelitian dianalisis bivariat menggunakan uji chi Square. 
Jurnal Kebidanan Harapan Ibu Pekalongan

\section{Hasil dan Pembahasan}

Analisis Univariat

Tabel 1. Tabel distribusi frekuensi pendidikan, pendapatan dan Status Gizi

\begin{tabular}{|c|c|c|}
\hline Variabel & $\begin{array}{c}\text { Jumlah } \\
\text { (n) }\end{array}$ & $\begin{array}{c}\text { Persen } \\
(\%)\end{array}$ \\
\hline \multicolumn{3}{|c|}{ Pendidikan orang tua } \\
\hline Pendidikan & 42 & $56 \%$ \\
\hline Tinggi & 33 & $44 \%$ \\
\hline \multicolumn{3}{|l|}{$\begin{array}{l}\text { Pendidikan } \\
\text { rendah }\end{array}$} \\
\hline \multicolumn{3}{|c|}{ Pendapatan orang tua } \\
\hline UMR & 31 & 41.3 \\
\hline diatas UMR & 44 & $\%$ \\
\hline Kurang dari & & 58.7 \\
\hline UMR & & $\%$ \\
\hline \multicolumn{3}{|c|}{ Pertumbuhan BB/TB } \\
\hline Normal & 60 & $80 \%$ \\
\hline Kurus & 15 & $20 \%$ \\
\hline \multicolumn{3}{|c|}{ Pertumbuhan TB/U } \\
\hline Normal & 45 & $60 \%$ \\
\hline Pendek & 30 & $40 \%$ \\
\hline
\end{tabular}

Dari hasil penelitian diatas dapat dilihat bahwa pendidikan orang tua paling banyak adalah pendidikan tinggi sebesar 56\% dengan melihat hasil penelitian ini dapat dikatakan bahwa pendidikan dikapubaten Semarang sudah maju dan sudah banyak yang memperoleh pendidikan sampai dipendidikan tinggi. Untuk pendapatan orang tua paling banyak adalah kurang dari UMR sebesar 58.7\%. hasil pengukuran pertumbuhan dengan menggunakan $\mathrm{BB} / \mathrm{TB}$ didapatkan hasil $80 \%$ dalampertumbuhan yang normal. Untuk pengukuran pertumbuhan dengan menggunakan $\mathrm{TB} / \mathrm{U}$ didapatkan pertumbuhan pendek seberar $30 \%$.

\section{Analisis Bivariat}

Tabel 2. Tabel analisis Chi Square Hubungan antara pendidikan orang tua dengan Pertumbuhan (BB/TB)

\begin{tabular}{|c|c|c|c|c|c|c|}
\hline \multirow[t]{2}{*}{$\begin{array}{l}\text { Kelompok } \\
\text { variable }\end{array}$} & \multicolumn{2}{|c|}{$\begin{array}{c}\text { Pertumbuhan } \\
(\mathrm{BB} / \mathrm{TB})\end{array}$} & \multirow[t]{2}{*}{ OR } & \multicolumn{2}{|c|}{ CI (95\%) } & \multirow[t]{2}{*}{$P$} \\
\hline & $\begin{array}{l}\text { Kurus } \\
(\%)\end{array}$ & $\begin{array}{c}\text { Normal } \\
(\%)\end{array}$ & & $\begin{array}{l}\text { Batas } \\
\text { bawah }\end{array}$ & $\begin{array}{c}\text { Batas } \\
\text { atas }\end{array}$ & \\
\hline $\begin{array}{l}\text { Pendidikan } \\
\text { Tinggi }\end{array}$ & $\begin{array}{c}4(5.3 \\
\%)\end{array}$ & $\begin{array}{c}38 \\
(50.7 \%)\end{array}$ & 4.750 & 1.349 & 16.730 & 0.011 \\
\hline $\begin{array}{l}\text { Pendidikan } \\
\text { rendah }\end{array}$ & $\begin{array}{c}11 \\
(14.7 \\
\%)\end{array}$ & $\begin{array}{c}22 \\
(29.3 \%)\end{array}$ & & & & \\
\hline
\end{tabular}

Dari hasil penelitian diatas didapatkan kesimpulan terdapat hubungan bermakna secara statistic dengan $\mathrm{p} 0.011$ dan OR 4.750 yang berarti pendidikan orang tua yang renadah akan mempunyai peluang 4 kali untuk mempunyai balita dengan pertumbuan kategori kurus. Hal ini sesuai dengan penelitian yang telah dilakukan Ni'mah dan Muniroh (2015) yang menyatakan ada hubungan antara tingkat pengetahuan orang tua dengan pertumbuhan yaitu dengan kejadian stunting dan wasting. Pendidikan orang tua sangat berpengaruh dengan proses menerima informasi dan melakukan perubahan, dengan pendidikan yang tinggi orang tua akan mudah diberikan penyuluhan dan mau melakukan perubahan perilaku yang mendukung ke pertumbuhan dan perkembangan anaknya, sedangkan pendidikan orang tua yang rendah lebih sulit untuk mau menerima informasi an melakukan perubahan perilaku. Hal ini akan sangat mempengaruhi pertumbuhan balita. ${ }^{(6)}$ 
Jurnal Kebidanan Harapan Ibu Pekalongan

Tabel 3. Tabel analisis Chi Square Hubungan antara pendidikan orang tua dengan Pertumbuhan (TB/U) Balita

\begin{tabular}{|c|c|c|c|c|c|c|}
\hline \multirow{2}{*}{ Kelompok variable } & \multicolumn{2}{|c|}{ Pertumbuhan (TB/U) } & \multirow{2}{*}{ OR } & \multicolumn{2}{|c|}{ CI $(95 \%)$} & \multirow{2}{*}{$\mathrm{P}$} \\
\hline & $\begin{array}{c}\text { Pendek } \\
(\%)\end{array}$ & $\begin{array}{c}\text { Normal } \\
(\%)\end{array}$ & & $\begin{array}{r}\text { Batas } \\
\text { bawah }\end{array}$ & $\begin{array}{c}\text { Batas } \\
\text { atas }\end{array}$ & \\
\hline Pendidikan Tinggi & $\begin{array}{c}9 \\
(12 \%)\end{array}$ & $\begin{array}{c}33 \\
(44 \%)\end{array}$ & 6.417 & 2.307 & $\begin{array}{c}17.84 \\
6\end{array}$ & 0.000 \\
\hline Pendidikan rendah & $\begin{array}{c}21 \\
(28 \%)\end{array}$ & $\begin{array}{c}12 \\
(16 \%)\end{array}$ & & & & \\
\hline
\end{tabular}

Hubungan antara pendidikan orang tua dengan pertumbuhan yang dilihat dengan TB / U didapatkan hasil signifikan secara statistic dengan $\mathrm{p}$ lebih kecil dari 0.01 dan OR 6.417 dengan demikian dapat disimpulkan bawa oraang tua dengan pendidikan rendah mempunyai peluang untuk mempunyai anak dengan pertumbuhan pendek sebesar 6 kali dibanding dengan orang tua yang mempunyai pendidikan tinggi. Penelitian ini sejalan dengan penelitian yang telah di lakukan oleh Nurmalasari, dkk (2020), dengan hasil terdapat hubungan antara pendidikan orag tua dengan kejadian Stunting dengan p 0.000 dan OR 3.313 dan terdapat hubungan antara pendapatan orang tua dengan kejadian stunting pada balita. Tingkat pendidikan ibu sangat mempengaruhi kesehatan keluarga termasuk pertumbuhan dan perkembangan balita nya. Hasil penelitian ini juga sejalan dengan hasil penelitian yang telah dilakukan oleh Dorsey, et.al (2016) yang menyatakan terdapat hubungan anatara pendidikan orang tua dengan kejadian stunting (pendek), orang tua yang mempunyai pendidikan rendah lebih rentan memiliki anak dengan Stunting. ${ }^{(7)}$

Tabel 4. Tabel analisis Chi Square Hubungan antara pendapatan orang tua dengan Pertumbuhan (BB/TB)

\begin{tabular}{lcccccc}
\hline Kelompok variable & \multicolumn{2}{c}{ Pertumbuhan (BB/TB) } & OR & \multicolumn{2}{c}{ CI (95\%) } & P \\
\cline { 2 - 3 } \cline { 5 - 6 } & $\begin{array}{c}\text { Kurus } \\
(\%)\end{array}$ & $\begin{array}{c}\text { Normal } \\
(\%)\end{array}$ & & $\begin{array}{c}\text { Batas } \\
\text { bawah }\end{array}$ & $\begin{array}{c}\text { Batas } \\
\text { atas }\end{array}$ & \\
\hline Pendapatan UMR & 3 & $28(37.3 \%)$ & 3.500 & 0.896 & 13.67 & 0.061 \\
dan diatas UMR & $(4 \%)$ & & & & 8 & \\
Pendapatan & 12 & $32(42.7 \%)$ & & & & \\
dibawah UMR & $(16 \%)$ & & & & & \\
\hline
\end{tabular}

Dari hasil penelitian diatas dinyatakan tidak signifikan secara statistik dengan hasil p 0.061 dan OR. 3,5. Hal ini berarti hubungan antara pendapatan orang tua dengan pertumbuhan yang diukur dengan menggunakan berat badan / tinggi badan tidak signifikan secara statistik atau dikatakan tidak terbukti ada hubungan. Hal ini sesuai dengan penelitian yang telah dilakukan oleh Astuti dan sulistyowati yang dilakukan di SD Godean dengan hasil tidak ada hubunghan antara tingkat pendidikan ibu dan pendapatan 
Jurnal Kebidanan Harapan Ibu Pekalongan

keluarga dengan ststus gizi anak prasekolah. Akan tetapi penelitian ini berbeda dengan hasil penelitian yag telah dilakukan oleh oleh Ni'mah dan Muniroh (2015) dengan judul hubungan tingkat pendidikan, tingkat pengetahuan dan pola asuh ibu dengan wasting dan stunting pada balita keluarga miskin, didapatkan hasil kejadian pendek atau stunting lebih besar daripada wasting atau kurus pada keluarga miskin. Indeks $\mathrm{BB} / \mathrm{TB}$ menggambarkan status gizi balita saat ini, yaitu menggambarkan apakah ststus gizi balita tersebut terpenuhi atau tidak. Pada penelitian ini didapatkan hasil tidak terdapat hubungan antara pendapatan dan pertumbuhan balita, menurut analisa peneliti karena tempat penelitian yang peneliti ambil adalah daerah pedesaan jadi masih ada hasil bumi yang dapat digunakan untuk memenuhi kebutuhan nutrisi balita selain dari pendapatan keluarga. ${ }^{(7),(10)}$

Tabel 5. Tabel analisis Chi Square Hubungan antara pendapatan orang tua dengan Pertumbuhan (TB/U) Balita

\begin{tabular}{lccccccc}
\hline Kelompok variable & \multicolumn{2}{c}{ Pertumbuhan (TB/U) } & OR & \multicolumn{2}{c}{ CI (95\%) } & P \\
\cline { 2 - 3 } \cline { 5 - 6 } \cline { 5 - 6 } & $\begin{array}{c}\text { Kurus } \\
(\%)\end{array}$ & $\begin{array}{c}\text { Normal } \\
(\%)\end{array}$ & & & $\begin{array}{c}\text { Batas } \\
\text { bawah }\end{array}$ & $\begin{array}{c}\text { Batas } \\
\text { atas }\end{array}$ & \\
\hline Pendapatan UMR & 8 & 23 & 0.415 & & 0.191 & 0.903 & 0.035 \\
dan diatas UMR & $(10.7 \%)$ & $(30.7 \%)$ & & & & & \\
Pendapatan & 22 & 22 & & & & \\
dibawah UMR & $(29.3 \%)$ & $(29.3 \%)$ & & & & \\
\hline
\end{tabular}

Hasil penelitian diatas dapat disimpulkan bawa hubungan antara pendapatan dengan pertumbuhan dinyatakan signifikan secara statistik, akantetapi dari OR nya 0.415 mendekati dengan satu yang dapat disimpulkan tidak ada beda antara pendapatan UMR serta diatas UMR dan dibawah UMR. Hasil penelitian ini sesuai dengan hasil penelitian yang telah dilakukan oleh Mulazimah tahun 2017 yang menyatakan terdapat hubungan antara pendapatan keluarga dengan dengan ststus gizi yang dinilai dengan ststus gizi baik, kurang dan gizi buruk. Dengan hasil penelitian ini terbukti bahwa pendapatan keluarga akan dapat menentukan asupan nutrisi yang diberikan ke keluarganya terutama ke anak balitanya Selain itu status gizi yang dinilai dengan menggunakan $\mathrm{TB} / \mathrm{U}$ menggambarkan bagaimana kondisi gizi pada masa yang lampau termasuk sejak dalam kandungan. ${ }^{(10)}$

\section{Kesimpulan}

Kesimpulan dari penelitian ini adalah terdapat hubungan antara pedidikan dan pendapatan orang tua dengan pertumbuhan (TB/U), terdapat hubungan antara pendidikan orang tua dengan pertumbuhan $(\mathrm{BB} / \mathrm{TB})$, dan tidak terdapat hubungan anatara pendapatan orang tua dengan pertumbuhan $(\mathrm{BB} / \mathrm{TB})$. 
Jurnal Kebidanan Harapan Ibu Pekalongan

\section{Daftar Pustaka}

[1] Dinkes Jateng. Profil Kesehatan Jawa Tengah 2019. Semarang, 2019.

[2] Kemenkes RI. Pedoman Pelaksanaan Stimulasi,Deteksi dan Intervensi Dini Tumbuh Kembang Anak di Tingkat Pelayanan Kesehatan Dasar. Jakarta: Kemenkes RI, 2015.

[3] Soetjiningsih dan Ranuh. Tumbuh Kembang Anak. Jakarta: EGC, 2015.

[4] UNICEF. Investasi pada Perkembangan Anak Usia Dini Penting untuk Membantu Anak dan Masyarakat, Temuan Lancet Series, 2016.

[5] Soediaoetama, Achmad Djaeni. Ilmu Gizi Jilid III Cetakan III. Jakarta: Dian Rakyat, 1999.

[6] Ni'mah, Muniroh, Hubungan Tingkat Pendidikan, Tingkat Pengetahuan dan Pola Asuh Ibu dengan Wasting dan Stunting pada Balita Keluarga Miskin, media giz Indonesia vol. 10, No.1 pp.84-90, 2015.

[7] Nurmalasari, Anggunan, Febriyany. Hubungan Tingkat Pendidikan Ibu Dan Pendapatan Keluarga Dengan Kejadian Stunting Pada Anak usia 6-59 bulan, jurnal kebidanan vol.6, no.2, pp. 205211, April 2020.

[8] Dorsey.J, Monahar. S, Neupane.S, Shrestha. B, Klemm. R, West. K, Individual, Household, And Community Level Risk Factors Of Stunting In Children Younger Than 5 Years: Findings from a national surveillance system in Nepal, 2016.
[9] Astuti, D, Sulistyowati., Hubungan Tingkat Pendidikan Ibu Dan Tingkat Pendapatan Keluarga dengan Status Gizi Anak Prasekolah dan Sekolah Dasar di Kecamatan Godean: Kes Mas, vol. 7, no.1, 2013.

[10] Mulazimah. Hubungan Pendapatan Keluarga dengan Status Gizi Balita Desa Ngadiluwih Kecamatan Ngadiluwih Kabupaten Kediri, 2017. 